\title{
MACHADO DE ASSIS \\ E O MULATO DE "ALMA GREGA"
}

\section{TEREZINHA V. ZIMBRÃO DA SILVA}

Universidade Federal de Juiz de Fora

Juiz de Fora, Minas Gerais, Brasil

Resumo: O presente trabalho discute o tema Machado de Assis e o mulato de "alma grega". O foco será a história literária brasileira, mostrando o contexto estético e ideológico da belle époque no Brasil: helenismo, europeísmo, racismo científico, mestiçagem e preconceito étnico. Também procurará mostrar que o romance machadiano Esaú e Jacó, publicado em 1904, pode ser interpretado como uma crítica dissimulada e sutil do escritor Machado de Assis ao preconceito étnico do período.

Palavras-chave: Machado de Assis; Crítica e Interpretação; Preconceito étnico.

\section{MACHADO DE ASSIS AND THE MULATTO WITH A "GREEK SOUL"}

Abstract: This essay discusses the theme Machado de Assis and the mulatto with a "greek soul". It will focus on Brazilian literary history, showing the aesthetic and ideological context of the Belle Époque in Brazil: Hellenism, Europeanism, scientific racism, miscegenation and ethnic prejudice. It will also show that the Machadean novel, Esaú e Jacó, published in 1904, can be interpreted as a dissimulated and subtle criticism by writer Machado de Assis of the ethnic prejudice of that period.

Keywords: Machado de Assis; Criticism and Interpretation; Ethnic Prejudice. 


\section{Introdução}

No caso da mostra do centenário de Machado [...]
[c]ausou impacto, em especial, o certificado de batismo do
escritor, que, atribuindo-lhe mãe branca, portuguesa e
alfabetizada, minimizava o estigma da mestiçagem.

CARDOSO, M. R.

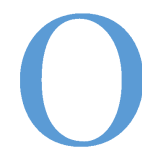

certificado de batismo de Joaquim Maria Machado de Assis foi exposto publicamente no centenário do nascimento do autor, em 1939. Eis o que está escrito na folha 167 do livro número 8 de registro de batismo da paróquia de Santa Rita:

Aos treze dias do mês de Novembro de mil oitocentos e trinta e nove annos na Capella da Senhora do Livramento filial a esta Matriz com Provizão do Illustrissimo e Reverendissimo Monsenhor, e Vigário Capitular Narcizo da Silva Nepomuceno, e minha licença o Reverendo Narcizo José de Moraes Marques baptizou, e pos os Santos Oleos a Joaquim, innocente filho legítimo de Francisco Jozé de Assis, e Maria Leopoldina Machado de Assis, elle natural desta Côrte, e Ella da ilha do Faial, digo, Ella da Ilha de São Miguel: forão padrinhos o Excellentissimo Viador Joaquim Alberto de Souza da Silveira, e Dona Maria Jozé de Mendonça Barrozo, nasceo aos vinte e hum de junho do prezente anno: de que fis este assento.

O Vigr. ${ }^{\circ}$ Jozé Francisco da Silva Cardoso. $^{2}$

Nota-se, entre os contemporâneos de Machado de Assis e mesmo entre os críticos machadianos de décadas depois, um esforço para minimizar no escritor o estigma da mestiçagem. A exposição pública do certificado de batismo de Machado de Assis em 1939, atribuindo-lhe mãe branca e portuguesa, da ilha de São Miguel, confirmava a observação de Joaquim Nabuco: "O Machado para mim era branco. [...] quando houvesse sangue estranho, isto em nada alterava a sua perfeita caracterização caucásica". 3

\footnotetext{
${ }^{1}$ CARDOSO, Arquivos em exposição, p. 76

${ }^{2}$ COSTA \& FRANCO, Machado de Assis, p. 49.

${ }^{3}$ NABUCO apud MASSA, A juventude de Machado de Assis, p. 46.
} 
Essa tentativa de embranquecer o escritor manifestou-se até mesmo na escolha dos retratos de Machado de Assis divulgados para o público em geral: foram selecionados preferencialmente aqueles em que a aparência de mulato comparecia atenuada pelo pincenê e pela barba. Eis a observação do crítico francês, Jean-Michel Massa:

Alguns o consideram como branco. Examinando os retratos que dele nos ficaram, nota-se que, adulto, tinha, como muitos brasileiros, alguns traços negroides: cabelos ligeiramente crespos, o lábio inferior bastante carnudo, um nariz antes achatado. Estes traços mais ou menos acentuados segundo os vários retratos, são bem encobertos pelo uso da barba. $^{4}$

Só recentemente, a afrodescendência de Machado de Assis e o tratamento que o escritor dá aos afrodescendentes em seus escritos se constituíram como objeto de reflexão da crítica machadiana. O crítico Eduardo de Assis Duarte, organizador da antologia Machado de Assis afrodescendente, explica: "O propósito deste trabalho é refletir sobre a natureza do pertencimento étnico do autor e sobre suas manifestações". Duarte sublinha que a questão étnica e a crítica ao escravismo estão presentes, sim, na obra machadiana, mas se manifestam de forma dissimulada, através de uma estratégia de "caramujo". Essa dissimulação deu margem à polêmica em torno do absenteísmo machadiano e da negação de suas origens negras. Duarte conclui:

No entanto, a partir da leitura dos textos presentes nessa Antologia torna-se impossível concordar com a ideia de um escritor omisso. [...] existe, sim, o pertencimento étnico traduzido em literatura [...]. Todavia, para refletir sobre as marcas da afrodescendência presentes nos textos não há como descartar as estratégias de caramujo empregada pelo autor. ${ }^{6}$

\footnotetext{
${ }^{4}$ MASSA, A juventude de Machado de Assis, p. 46-47.

${ }^{5}$ DUARTE, Machado de Assis afrodescendente - escritos de caramujo (antologia), p. 253.

${ }^{6}$ Ibidem.
} 
É, portanto, com estratégias de caramujo, ou seja, de modo dissimulado e não explícito, que o pertencimento étnico comparece na obra machadiana. E é assim, sobretudo, que este tem sido estudado pela crítica machadiana mais recente, para a qual pretende contribuir o presente trabalho quando se propõe refletir sobre o tema: Machado de Assis e o mulato de "alma grega".

No auge da belle époque, período de intenso europeísmo no Brasil, houve a "mania da Grécia" (a expressão é de Brito Broca), ${ }^{7}$ a qual consideramos um bom exemplo de refúgio dos escritores brasileiros ao preconceito da inferioridade étnica - preconceito alimentado pelo racismo científico então em vigor no Ocidente e responsável pelo ideal de embranquecimento de que foi objeto o próprio Machado de Assis. Procuraremos mostrar que o escritor adota uma postura das mais críticas, ainda que dissimulada, em relação a essa "mania" e, portanto, em relação ao próprio preconceito da inferioridade étnica.

\section{A "mania" da Grécia}

[O] preconceito da inferioridade étnica [...] levava os [...] escritores a se refugiarem na Grécia. ${ }^{8}$

BROCA, B.

[E]ssa mania da Grécia [...] era um meio, por vezes inconsciente, de muitos intelectuais brasileiros reagirem contra a increpação da mestiçagem. ${ }^{9}$

BROCA, B.

Quando o escritor Machado de Assis lançou Esaú e Jacó, em 1904, a Grécia havia certo tempo já habitava de novo o meio literário brasileiro. Com efeito, desde as manifestações iniciais do Parnasianismo nos fins do século XIX, o encanto pelos deuses do Olimpo, que declinara ao longo do Romantismo, retornou exultante e veio a perseverar assim até a Primeira Guerra Mundial, pelo menos. Um escritor não podia julgar-se perfeitamente culto caso não citasse os helenos. Deles fizeram uso e abuso Coelho Neto, Olavo Bilac, João do Rio, Monteiro Lobato, dentre vários outros.

\footnotetext{
${ }^{7}$ BROCA, A vida literária no Brasil - 1900, p. XX.

${ }^{8}$ Idem, p.107.

${ }^{9}$ Idem, p. 105.
} 
Um aspecto importante dessa mania era o próprio exagero. A este respeito, afirma o crítico Brito Broca: "a Grécia triunfou plenamente em nossas letras [...]. Alguns citavam-na a cada passo [...]". ${ }^{10} \mathrm{E}$ sublinha: "Era geralmente uma Grécia de cartolina, puramente decorativa". ${ }^{11}$ Notemos que o Parnasianismo no Brasil, estendendo-se até as vésperas da Semana de Arte de 1922, propagou até então um exagerado culto aos clássicos da Antiguidade.

Respondendo ao amigo Mário de Alencar e ao seu intento de escrever um poema a respeito de Prometeu, Machado de Assis afirmava em carta de 1908 que tornara a ler por aqueles dias o Prometeu e o Fedon, sumarizando então: "veja como ando grego, meu amigo". ${ }^{22}$ Mas, segundo Broca: "Machado de Assis foi, no entanto, dos poucos que souberam subtrair-se a essa influência; envolvendo personagens gregos em alguns contos, emprestoulhes quase sempre um caráter satírico". ${ }^{13}$

Com efeito, Machado de Assis já tinha ironizado essa "mania" dos clássicos e a sua superficialidade desde o final do oitocentos, quando escreveu o conto "Teoria do medalhão". Eis que nos deparamos então com um diálogo, em que um pai doutrina o filho a elaborar uma intelectualidade de aparências, persuadindo-o de que esta era uma cláusula essencial a fim de se ter sucesso no Brasil da belle époque. Dentre os ensinamentos que o pai transmite ao filho, destacamos a parte referente à citação dos clássicos com o intuito de adornar o estilo:

[P]odes [diz o pai] empregar umas quantas figuras expressivas, a hidra de Lerna, por exemplo, a cabeça de Medusa, o tonel das Danaides, as asas de Ícaro, e outras [...]. Sentenças latinas [...], versos célebres [...] é de bom aviso trazê-los contigo para os discursos [...] [e também] para fecho de artigos políticos. [...]. Não [o]s relaciono agora, mas fá-lo-ei por escrito. $^{14}$

Notemos que o ensinamento diz para citar os clássicos tendo por base uma relação elaborada pelo pai, sendo desnecessário que o filho, de fato, os

\footnotetext{
${ }^{10}$ Idem, p. 102.

${ }^{11}$ Ibidem.

${ }^{12}$ ASSIS, Obra completa, vol. 3, p. 1086.

${ }^{13}$ BROCA, cit., p. 102.

${ }^{14}$ ASSIS, cit., vol. 2, p. 291.
} 
tenha lido. Isto se explicita mais adiante, no momento em que o pai sublinha: "o método de interrogar os próprios mestres [...] [é] tedioso e cansativo". ${ }^{15} \mathrm{E}$ claro que Machado de Assis estava sendo irônico ao colocar o seu personagem dando este conselho "medalhístico".

Ora, o helenismo decorativo e superficial manifestou-se na maioria dos escritores da belle époque. O próprio advento do futebol no Brasil, na primeira década do século XX, começou a ser encarado pela perspectiva helênica. E não só o futebol, pois como acrescenta Brito Broca: "Era assim: regatas, jogos olímpicos, futebol, todos os esportes não podiam ser vistos de outra maneira, senão através da Grécia". ${ }^{16}$

A visita do escritor francês Anatole France ao Brasil e sua afirmação de que os brasileiros representavam uma feliz transplantação dos greco-latinos contribuíram para alimentar a "mania", assim "reforçando a certeza de que éramos gregos". ${ }^{17}$ Euclides da Cunha reivindicava uma origem helênica, definindo-se como um misto de celta, de tapuia e grego. O filósofo Tobias Barreto já no final do oitocentos declarava ser grego, pequeno e forte. Contudo, há nessa "mania" da Grécia um aspecto sociológico digno de nota, como sublinha Brito Broca:

[A] questão apresenta outra face, um aspecto sociológico digno de ser posto em realce. Essa mania da Grécia, [...] que de há muito prevalecia entre nós, era um meio, por vezes inconsciente, de muitos intelectuais brasileiros reagirem contra a increpação da mestiçagem, escamoteando as verdadeiras origens raciais, num país em que o cativeiro estigmatizara a contribuição do negro. ${ }^{18}$

Consideremos que, na sociedade brasileira da belle époque, a mestiçagem era vista como um sinal de decadência, mirava-se então o espelho do branco europeu, pois o que se queria ver era a imagem do embranquecimento do brasileiro. De onde, possivelmente, a motivação dos escritores do tempo para abraçar a condição literária de grego. Supondo-se assim, contornavam a alegada decadência da mestiçagem.

\footnotetext{
${ }^{15}$ Idem, p. 292.

${ }^{16}$ BROCA, cit., p. 104.

${ }^{17}$ Idem, p. 107.

${ }^{18}$ Idem, p. 105.
} 
Em carta de 1908, Monteiro Lobato contava a Godofredo Rangel que estava naquele momento lendo Homero e sublinhava: "Estive uns dias no Rio. Que contra-Grécia é o Rio! O mulatismo dizem que traz dessoramento do caráter [...]. Isso no moral - e no físico, que feiura!". E acrescentava: "Que diferença de mundos! Na Grécia, a beleza; aqui a disformidade. Aquiles lá; Quasímodo aqui". Mais adiante: "Os negros da África, caçados a tiro e trazidos à força para a escravidão, vingaram-se do português da maneira mais terrível - amulatando-o". E finalizava: "Como consertar essa gente? [...] Que problemas terríveis o pobre negro da África nos criou aqui na sua inconsciente vingança! Talvez a salvação venha de São Paulo e outras zonas que intensamente se injetam de sangue europeu". ${ }^{19}$

Notemos, portanto, que o preconceito da inferioridade étnica motivava os escritores a se refugiarem na "mania" da Grécia. De fato, no Parnasianismo brasileiro, o helenismo assumiu o papel de uma genuína Torre de Marfim, refúgio onde os escritores se distanciavam das "disformidades" da realidade local. Lá do topo, esta Grécia mirava com olhar soberbo o Brasil embaixo, tão perto e tão distante.

Não é um tal distanciamento o que vamos encontrar ao lermos Esaú e Jacó. Pelo contrário, realidade local e Grécia irão se confundir no romance machadiano. Afinal, como mencionou Broca, Machado de Assis foi um dos poucos que souberam, de fato, subtrair-se à "mania" da Grécia. Pois vejamos.

\section{A Pitonisa cabocla}

Você quer ver que elas vão à cabocla? ${ }^{20}$

ASSIS, J. M. M.

Nas primeiras páginas de Esaú e Jacó, deparamos com a consulta de uma dama da alta sociedade fluminense dos idos do oitocentos a uma popular adivinha. Natividade, na companhia da irmã Perpétua, deixara a sua casa no rico bairro de Botafogo e subia então, machucando os pés no mal calçado da ladeira, ao marginalizado morro do Castelo, um lugar onde moravam pessoas pobres: lavadeiras, soldados, lojistas. ${ }^{21}$

\footnotetext{
${ }^{19}$ LOBATO apud BROCA, cit., p. 107.

${ }^{20}$ ASSIS, cit., vol. 1, p. 947.

${ }^{21}$ Ibidem.
} 
Dirigindo-se ao leitor de um tempo positivista e preconceituoso em relação ao conhecimento não científico, o narrador logo recomenda: "não há que dizer do costume que é velho e velhíssimo". ${ }^{22}$ De fato, o costume de se aconselhar com um oráculo a respeito das cousas futuras é tão velho que aparece na literatura grega de dois milênios atrás, é o que o narrador recorda ao leitor quando adverte: "Relê Ésquilo, meu amigo, relê as Eumênides, lá verás [...] os que iam à consulta". 23

Assim, ao descrever a consulta de uma elegante dama a uma popular adivinha, o narrador, antevendo os preconceitos positivistas, recomenda ao leitor que releia em um clássico da literatura universal como As Eumênides, de Ésquilo, a descrição igualmente de uma consulta oracular. E, com efeito, se o leitor reler a conhecida tragédia esquiliana, lá encontrará o príncipe Orestes seguindo até a privilegiada localidade montanhosa de Delfos a fim de se aconselhar com o venerável oráculo da sacerdotisa Pítia a respeito do seu incerto futuro depois de ter assassinado a própria mãe, como vingativa resposta pelo assassínio do seu pai Agamenon. ${ }^{24}$

Contudo, sabemos que a razão para Natividade ir ao marginalizado morro do Castelo, aconselhar-se não com uma venerável sacerdotisa, e sim com uma popular adivinha, é muito menos trágica: esta mãe tão somente gostaria de saber se os seus dois gêmeos de pouco mais de um ano se tornariam grandes e gloriosos. São grandes as disparidades entre ambos os textos: um é uma clássica tragédia, o outro é um romance moderno e "folhetinesco". Todavia, a alusão machadiana a Ésquilo, que é citado nas páginas iniciais de Esaú e Jacó, explicitamente aproxima os dois oráculos.

De fato, Machado de Assis coloca então, em surpreendente convivência, o oráculo clássico e o prosaico. Em atitude contrária à de outros escritores do tempo, que escolhiam o distanciamento cosmopolita da Torre de Marfim em relação à realidade local, o Bruxo do Cosme Velho, ao citar a tragédia no seu romance, faz com que a tradição helênica com o seu colorido puro e sublime conviva com a modernidade brasileira e suas cores mestiças, prosaicas e supostamente vulgares.

Assim, em Esaú e Jacó, o venerável oráculo da sacerdotisa Pítia de Delfos convive com o marginalizado oráculo de uma popular adivinha do morro do Castelo, a respeito da qual o narrador adiciona o significativo

\footnotetext{
${ }^{22}$ Idem, p. 948.

${ }^{23}$ Ibidem.

${ }^{24}$ ÉSQUILO, Oréstia III: Eumênides.
} 
detalhe de se tratar de uma cabocla. Notemos que Machado de Assis reencena, nos tempos modernos, o clássico tema da consulta a um oráculo e escolhe justo uma mestiça - uma cabocla - para no prosaico palco do Brasil interpretar, como a adivinha do morro do Castelo, o papel da grega Pítia de Delfos. Consideremos que o caboclo veio a ser marginalizado por uma sociedade que, em sua situação periférica, se via obrigada a mirar-se no espelho do branco europeu, almejando o embranquecimento. Colocar no papel da grega a brasileira cabocla é desafiar a distância cosmopolita da Torre de Marfim.

Um dado importante que Machado de Assis cuidou então de registrar é o sincretismo étnico-religioso. A começar pelo detalhe de ter posicionado uma dama católica a se aconselhar com uma adivinha, que por seu turno é uma cabocla portadora do mesmo nome de uma santa do catolicismo: Bárbara. Sendo que esta santa Bárbara está dentre aquelas a ter um equivalente sincrético na religião afro-brasileira que é o orixá Iansã. E mais, descreveu a adivinha cabocla usando um raminho de arruda (um talismã contra má sorte, conhecido entre os negros), além de catolicamente ter a imagem de Nossa Senhora da Conceição pendurada na parede do aposento onde efetua o ritual oracular, que será seguido pela fumaça do cigarro que ela então acende e pela canção de tema africano acompanhada na viola pelo pai, igualmente caboclo.

Logo, o persistente misticismo local, em todo o seu sincretismo, está registrado no texto machadiano. De fato, Machado de Assis nos descreve um Brasil que não é tão católico, nem tampouco branco como se desejava então, mas onde estes traços europeus, associados à cultura oficial, apresentam-se em convivência sincrética com a marginalizada cultura popular. O romance revela assim raízes "inconfessadas" da identidade cultural brasileira, o que comprova o aspecto crítico do pensamento machadiano a respeito do europeísmo e das "manias" dominantes no Brasil da belle époque.

\section{Presente de Grego}

A palavra não é literária e é pejorativa [...]. Eu pelo menos só vi nele o grego. 25 NABUCO apud MASSA

${ }^{25}$ NABUCO apud MASSA, cit., p. 46. 
Em carta a José Veríssimo após a morte de Machado de Assis em 1908, Joaquim Nabuco fazia o seguinte protesto contra o fato de se chamar o escritor de mulato:

Seu artigo no Jornal está belíssimo, mas esta frase causou-me arrepio: "Mulato, foi de fato um grego da melhor época". Eu não o teria chamado mulato e penso que nada lhe doeria mais do que essa síntese. Rogo-lhe que tire isso, quando reduzir o artigo a páginas permanentes. A palavra não é literária e é pejorativa. O Machado para mim era branco, e creio que por tal se tomava: quando houvesse sangue estranho, isto em nada afetava a sua perfeita caracterização caucásica. Eu pelo menos só vi nele o grego. ${ }^{26}$

Notemos que Nabuco se recusava a ver no amigo o mulato para só ver o grego - o mulato de "alma grega". Pois o Bruxo do Cosme Velho, com a sua pitonisa cabocla de Esaú e Jacó, conseguiu conciliar as duas imagens, a "pejorativa" do mulato e a literária do grego - imagens que para o amigo Nabuco e muitos outros contemporâneos eram inconciliáveis.

Neste sentido, seria razoável afirmar que a "pitonisa" cabocla de Machado de Assis sugere-se como uma crítica ao isolamento do intelectual local no alto cosmopolita da torre de marfim. Convivem na personagem a sublimidade da referência literária e a "vulgaridade" da realidade "pejorativa". Pois esta convivência de imagens, supostamente tão contrastantes, teria originado no "pensamento grego" deste romance machadiano um "sentido irônico", já observado pelo crítico Eugênio Gomes que, sobre o tema, escreveu:

[...] os reflexos do pensamento grego em Esaú e Jacó adquirem, às vezes, um sentido entre irônico e humorístico [...] será lícito afirmar que o romance envolve uma sátira sutil, mas sátira, à preamar de ideias, imagens e comparações gregas com que a nossa literatura foi inundada no começo deste século? ${ }^{27}$

Gomes percebe a peculiaridade do helenismo machadiano em comparação ao dos demais escritores contemporâneos. Machado de Assis

${ }^{26}$ Ibidem.

${ }^{27}$ ASSIS, cit., vol. 3, p. 1100. 
estaria, na verdade, de modo sutil e dissimulado, criticando e satirizando a "mania" da Grécia durante a belle époque. O distanciamento cosmopolita da Torre de Marfim, característico de outros escritores, é então desafiado: realidade local e Grécia convivem no romance Esaú e Jacó. O peculiar helenismo machadiano nos induz, portanto, a interpretá-lo como um verdadeiro "presente de grego" de Machado de Assis à "mania" da Grécia e também ao preconceito da inferioridade étnica que motivou Nabuco a ver no amigo só o grego - o mulato de "alma grega".

\section{Referências}

ASSIS, Machado de. Obra completa, vol. I. Rio de Janeiro: Nova Aguilar, 1997. Obra completa, vol. II. Rio de Janeiro: Nova Aguilar, 1997. Obra completa, vol. III. Rio de Janeiro: Nova Aguilar, 1997.

BROCA, Brito. A vida literária no Brasil - 1900. Rio de Janeiro: José Olympio, 1975. CARDOSO, Marília Rothier. Arquivos em exposição. Ipotesi, vol. 4, n. 2, jul./dez. 2000. Juiz de Fora: Ed. UFJF, 2000, p. 65-77.

COSTA, Pedro Pereira da Silva; FRANCO, Afonso Arinos de Mello. Machado de Assis. São Paulo: Ed. Três, 1981.

DUARTE, Eduardo de Assis (org). Machado de Assis afrodescendente - escritos de caramujo (antologia). Rio de Janeiro/Belo Horizonte: Pallas/Crisálidas, 2007.

ESQUILO. Oresteia III: Eumênides. Tradução de Jaa Torrano. São Paulo: Iluminuras, 2005.

GOMES, Eugênio. O testamento estético de Machado de Assis. In: ASSIS, Machado de. Obra completa, vol. III. Rio de Janeiro: Nova Aguilar, 1997, p. 1097-1120.

MASSA, Jean-Michel. A juventude de Machado de Assis. Tradução de M. A. de M. Matos. Rio de Janeiro: Civilização Brasileira, 1971.

TERESINHA VÂNIA ZIMBRÃO da Silva é doutora em Literatura (University of Newcastle Upon Tyne - 1994) e pós-doutora em Literatura (PUC-RJ -2007). Trabalha como professora associada da graduação e pós-graduação em Letras (mestrado e doutorado em Estudos Literários) da Universidade Federal de Juiz de Fora. Publicou: "O comunismo nas letras brasileiras: a década de 30", na revista Língua e Literatura da USP (2012), "Literatura, psicologia e alquimia" na revista História, imagem e narrativa (2013) e "Pagu e o romance proletário" na revista Litteris (2014). E-mail: <teresinha.zimbrao@ufjf.edu.br> 
Recebido: 28.08 .14

Aprovado: 30.10 .14 